\title{
Reliability and Clinical Significance of the Pediatric Balance Scale (PBS) in the Greek Language in Children Aged 4 to 18 Years
}

\section{Victoria Laspa1, Thomas Besios², Alexandra Xristara², George Tsigaras³, Maria Milioudi3, Savvas Mauromoustakos ${ }^{4}$, Stauros Kottaras ${ }^{4}$}

${ }^{1}$ Department of Physiotherapy, International University of Greece, Thessaloniki, Greece

${ }^{2}$ Lamia Physiotherapy Department, University of Thessaly, Thessaly, Greece

${ }^{3}$ Hippokratio General Hospital, Thessaloniki, Greece

${ }^{4}$ Department of Physical Therapy, International University of Greece, Thessaloniki, Greece

Email:^m.milioudi@yahoo.com, victorialsp@gmsil.com, tombesios@yahoo.gr,hristara2@hotmail.com, savvas@pmf.gr,

skotaras@yahoo.gr, tsigarasphysiopediatric@gmail.com

How to cite this paper: Laspa, V., Besios, T., Xristara, A., Tsigaras, G., Milioudi, M., Mauromoustakos, S. and Kottaras, S. (2020) Reliability and Clinical Significance of the Pediatric Balance Scale (PBS) in the Greek Language in Children Aged 4 to 18 Years. Open Journal of Preventive Medicine, 10 , 73-81.

https://doi.org/10.4236/ojpm.2020.105005

Received: March 20, 2020

Accepted: May 26, 2020

Published: May 29, 2020

Copyright $\odot 2020$ by author(s) and Scientific Research Publishing Inc. This work is licensed under the Creative Commons Attribution International License (CC BY 4.0).

http://creativecommons.org/licenses/by/4.0/

(c) $\underset{\mathrm{By}}{\mathrm{By}}$ Open Access

\begin{abstract}
Introduction: In recent years, many tests have been developed to assess the mobility and functional capacity of children with motor dysfunctions. The Pediatric Balance Scale (PBS) is a qualitative assessment test of the motor behavior of children aged 4 to 18 years. Purpose: The purpose of the proposed research is to determine the external reliability of the test Pediatric Balance Scale translated for the first time in Greek in children aged 4 to 18 years, in order to have a reliable tool in the hands of experts. Method: 26 children (14 girls and 12 boys with an average age of $\pm 10,673$ years of age) participated in this research. The Greek adaptation of the PBS and a Nikon 5300 digital camera for video recording were used for data collection. Results: The results found that there were no statistically significant differences between the two independent evaluators and that the Pediatric Balance Scale test had strong reliability. Overall, the results of the present investigation provided considerable evidence suggesting that the Greek adaptation of the PBS test has good inter-rater reliability and can be used to detect kinetic disorders in children aged 4 to 18 years for the Greek population.
\end{abstract}

\section{Keywords}

PBS, Children, Evaluation, Reliability 


\section{Introduction}

Stability and balance are primary characteristics of the human body, which are controlled and determined by various factors. Anatomically individual stands against gravity through a bone system. But muscles also have a significant share in achieving and maintaining balance and posture through kinetic standards [1].

All human activities require control, stability and balance. Primary motor skills, such as walking, standing and seating, depend on the ability of posture control [2] [3] [4] [5].

The balance is defined as the ability to control the centre of gravity of the body mass relative to the base of support. The balance depends on: the body support base, the position of the center of gravity and the line of gravity. In the context of the International Classification of Functioning, Disability and Health (International Classification of Functioning, Disability and Health), which was created by the World Health Organization, balance is described as both structure/function and activity. Balance is an important functional ability that significantly affects man's ability to perform daily activities for his survival such as: maintaining a stable posture, steadily moving from one position to another, maintaining upright posture, and much more [6].

When performing physiological activities in daily life, the person displays two types of balance, static and dynamic. It is important for normal development the static developed before dynamic balance in order to perform motor skills [7]. For the proper practice of balance, as already known, there is a low correlation between dynamic and static balance, which is why they should be detected and practiced separately [8]. Balance is one of the most basic motor abilities the child develops. For the purposes of this study, functional balance in children was defined as the ability to maintain the body mass weight center in relation to the support base in typical children's activities of daily life, school activities and outdoor playing.

Cerebral Palsy (CP) is a group of permanent cerebral disorders, which are attributed to lesions or abnormal cerebral development during prenatal or perinatal stage. Symptoms include poor motor control, muscle stiffness and in some cases, skeletal deformations which lead to poor balance [3] [9].

The Pediatric Balance Scale is a modified version of the Berg Balance Scale that is used to assess functional balance skills in school-aged children, from typically developing children and children with motor impairments. The scale consists of 14 items that are scored from 0 points (lowest function) to 4 points (highest function) with a maximum score of 56 points [10].

Its purpose is to assess the functional balance and motor disorders of school-age children with mild to moderate motor dysfunctions in the context of daily tasks. PBS also has the ability to distinguish normal children with those with mild motor damage, as well as those with moderate to severe motor impairment. Several studies on the reliability and validity of the test have been published [9] [11] [12].

Franjoine, Gunther and Taylor (2003) [9] suggested that PBS is reliable when 
used in school-age children with mild to moderate mobility problems. Jin-Gang Her, Ji-Hea Woo and Jooyeon, (2012) [13], demonstrated PBS high absolute reliability, so the test was considered a reliable tool for examining the functional balance of children with cerebral palsy. Snehal, Vijaymuniraj and Solomon (2011) [14], also concluded that the PBS is a valid scale and therefore suggested PBS in clinical studies to assess balance in children. Ries, Michaelsen, Soares, Monteiro and Allegretti (2012) [15], demonstrated that the Brazilian version of PBS should help assessing the balance of Brazil's pediatric population with CP. Yi, Hwang, Kim and Kwon (2012) [12], found that PBS can be considered a simple but valid scale to examine the capacity of functional balance in children with spastic CP. Duarte, Grecco, Franco, Zanon and Oliveira (2014) [16], in their study demonstrated that clinicians and researchers can use PBS clinical data to determine children's treatment and monitoring. Jantakat, Ramrit, Emasithi and Siritaratiwat (2015) [17], concluded that BBS and PBS are valid and reliable tools for clinical examination and the distinction between GMFCS-E \& R I to IV levels in adolescents with cerebral palsy.

\section{Method}

\subsection{Participants}

Participants consisted of 26 children (14 girls and 12 boys with an average age of $\pm 10,673$ years). The participants had been previously diagnosed with neurological disorders (cerebral palsy, Down syndrome) by a neurologist or/and a child neurologist. The clinicians that were treating them suggested a PBS evaluation. The participants were selected based on that they could follow the instructions, they had no other complications that could interfere with the procedure (range of motion of the hips, knees, ankle joints and shoulder flexion etc). All the participants were receiving physical therapy, functional level (mild and moderate) Table 1.

\subsection{Assessment Tool}

Data were obtained with the use of the following instruments:

- The Greek translation of the Pediatric Balance Scale. This assessment consists of a video-recording for approximately 20 minutes of the kinetic behavior in sitting, upright position and movement. It consists of 14 items based on activities of everyday life, starting from the easiest and ending in the most difficult. Each PBS item is scored on a 5-point scale with zero indicating that child cannot perform the activity without assistance and four indicating that child can perform the activity independently.

- For the children video recordings, a digital camcorder (Nikon 5300) was used.

\subsection{PBS Adaptation Procedure}

First, bilingual experts in pediatric physiotherapy translated the English version 
of the PBS into Greek, and then two independent bilingual interpreters, also experts in the domain of pediatric physiotherapy, translated the same instrument back into English. The original English version was then compared with the back-translated version and errors and discrepancies were identified. The back-translation comparison process was repeated until all discrepancies were eliminated. The final version exhibited no contradictions with the original English version of the measures when back-translated.

A pilot study was initially conducted with 10 children to determine if the research process was going well and whether there were any problems with both the translation of the test and the scoring.

After everything worked out properly with the pilot study, then the main research was conducted with the 26 children and their scoring by the two independent researchers.

Table 1. Children characteristics who participated in the research.

\begin{tabular}{|c|c|c|c|}
\hline NUMBER & AGE & SEX & CONDITION-FUNCTIONAL LEVEL \\
\hline 1 & 4 & FEMALE & DIPLEGIA- MILD \\
\hline 2 & 14 & FEMALE & HEMIPLEGIA- MILD \\
\hline 3 & 18 & FEMALE & DIPLEGIA-MILD \\
\hline 4 & 12 & FEMALE & HEMIPLEGIA- MILD \\
\hline 5 & 18 & FEMALE & HEMIPLEGIA-MODERATE \\
\hline 6 & 11 & MALE & HEMIPLEGIA- MILD \\
\hline 7 & 18 & FEMALE & TETRAPLEGIA-MILD \\
\hline 8 & 15 & FEMALE & TETRAPLEGIA-MILD \\
\hline 9 & 5 & MALE & HYPOTONIA-MODERATE \\
\hline 10 & 6 & FEMALE & DIPLEGIA-MILD \\
\hline 11 & 4 & MALE & TETRAPLEGIA-MILD \\
\hline 12 & 9 & MALE & TETRAPLEGIA-MILD \\
\hline 13 & 9 & MALE & DIPLEGIA-MILD \\
\hline 14 & 14 & MALE & TETRAPLEGIA-MILD \\
\hline 15 & 8 & MALE & HEMIPLEGIA-MODERATE \\
\hline 16 & 7 & FEMALE & HYPOTONIA-MILD \\
\hline 17 & 12 & FEMALE & DIPLEGIA-MILD \\
\hline 18 & 7 & MALE & DOWN SYNDROME-MILD \\
\hline 19 & 6.5 & MALE & DOWN SYNDROME-MILD \\
\hline 20 & 8 & FEMALE & HEMIPLEGIA-MILD \\
\hline 21 & 13 & FEMALE & TETRAPLEGIA-MILD \\
\hline 22 & 8.5 & MALE & HEMIPLEGIA-MILD \\
\hline 23 & 14 & MALE & DIPLEGIA-MILD \\
\hline 24 & 14 & FEMALE & TETRAPLEGIA-MILD \\
\hline 25 & 14 & MALE & HEMIPLEGIA-MODERATE \\
\hline 26 & 9 & FEMALE & DIPLEGIA-MILD \\
\hline
\end{tabular}




\subsection{Data Analysis}

To examine the reliability of the PBS translated into Greek, inter-rater reliability scores were computed via intra-class correlation coefficients (ICC), using two-way random model, with absolute agreement in the test results between the two independent researchers. Poor ICC values are considered scores below 0.50, whereas values from 0.50 to 0.75 are considered moderate and above 0.75 are considered as good. The significance of the results was determined by a $95 \%$ confidence interval (CI) using SPSS v.22. For each of the 14 tests separately, Cohen's Kappa statistical index was used, which test the agreement between observers [18].

The Spearman correlation coefficient, which is a non-parametric statistical measure, was also used to find the statistical dependence between two variables

\section{Results}

The results show that there is excellent reliability in all classes of the instrument for all age levels of the sample. For pilot reliability measurements, reliability scores (Table 2) were acceptable to excellent agreement for all subscales. As for the main study of the Greek adaptation of the PBS (Table 3, Table 4), results showed excellent agreement for all subscales and sample.

Tables 2-4, showed excellent agreement for all PBS subscales and sample ages. As for the pilot testing of the Greek version of the PBS, results (Table 2) showed excellent agreement. In particular, the ICC factors for the overall scores are in total greater than 0.992. As for the main study of the Greek version of the PBS (Table 3 and Table 4), results showed also excellent agreement for all subscales and sample ages.

For PBS test, Table 5 showed agreement from an acceptable 0.49 trial 3rd to excellent 0.867 trial 8 th in the Kappa index, while the Spearman factor ranged from 0.773 to 1.00 . As an outcome, for the PBS test the results indicate moderate to high reliability and the test can be used in the Greek population.

\section{Discussion}

This study has examined the determination of the external reliability of the Pediatric Balance Scale test translated for the first time in Greek in children aged 4 to 18 years, in order to have a reliable tool in the hands of the experts, both for evaluation the functional balance of school-age children with mild to moderate motor dysfunctions, as well as for the evaluation of motor disorders in the context of daily tasks. The data have indicated that there were no statistically significant differences between the two independent evaluators and that the Pediatric Balance Scale test had strong inter-rater reliability.

In particular, the results showed for the overall score strong PBS reliability (ICC $=0.992)$ with variance (ICC $=0.959-0.998)$. Also, the statistics suggested for the overall score almost excellent reliability among observers (ICC $=0.992)$ with variance (ICC $=0.960$ 0.998). As for each test separately, there was high re- 
liability with the Kappa index ranging from 0.49 to 1.00 in some tests and the Spearman factor ranging from 0.773 to 1.00 . These results are in line with the findings of Silkwood, Killian, Long, Martin, (2012) [19], which demonstrated that chivalry is a sustainable therapeutic strategy to improve the balance and functional performance of everyday skills life in children with mild to moderate balance problems.

Table 2. Score from the ICC index of the pilot study of the overall score of all PBS categories.

\begin{tabular}{lccccc}
\hline \multicolumn{4}{c}{ Intraclass Correlation Coefficient } \\
& Intraclass & \multicolumn{2}{c}{$\begin{array}{c}\text { 95\% Confidence Interval } \\
\text { Correlation }\end{array}$} & F Test with True Value 0 \\
\cline { 3 - 6 } & 0.985 & Lower Bound & Upper Bound & Value & df1 \\
\hline Single Measures & 0.922 & 0.997 & 158,079 & 7 \\
Average Measures & $\mathbf{0 . 9 9 2}$ & $\mathbf{0 . 9 5 9}$ & $\mathbf{0 . 9 9 8}$ & 158,079 & 7
\end{tabular}

Table 3. Total scores of the participants.

\begin{tabular}{|c|c|c|}
\hline Participants & Researcher 1 Total scores & Researcher 2 Total scores \\
\hline 1 & 37 & 36 \\
\hline 2 & 52 & 52 \\
\hline 3 & 51 & 50 \\
\hline 4 & 56 & 56 \\
\hline 5 & 56 & 56 \\
\hline 6 & 56 & 56 \\
\hline 7 & 51 & 48 \\
\hline 8 & 56 & 56 \\
\hline 9 & 48 & 47 \\
\hline 10 & 56 & 56 \\
\hline 11 & 29 & 26 \\
\hline 12 & 52 & 51 \\
\hline 13 & 49 & 47 \\
\hline 14 & 56 & 56 \\
\hline 15 & 56 & 56 \\
\hline 16 & 56 & 56 \\
\hline 17 & 56 & 55 \\
\hline 18 & 49 & 48 \\
\hline 19 & 46 & 46 \\
\hline 20 & 56 & 56 \\
\hline 21 & 44 & 42 \\
\hline 22 & 54 & 52 \\
\hline 23 & 56 & 55 \\
\hline 24 & 55 & 55 \\
\hline 25 & 56 & 56 \\
\hline 26 & 56 & 55 \\
\hline
\end{tabular}


Table 4. Score of the ICC index of the total PBS score.

\begin{tabular}{lccccc}
\hline \multicolumn{5}{c}{ Intraclass Correlation Coefficient $^{\circ}$} \\
\hline & $\begin{array}{c}\text { Intraclass } \\
\text { Correlation }\end{array}$ & \multicolumn{2}{c}{ 95\% Confidence Interval } & F Test with True Value 0 \\
\cline { 3 - 6 } & & Lower Bound & Upper Bound & Value & df1 \\
\hline Single Measures & $0.985^{\mathrm{a}}$ & 0.922 & 0.995 & 214,082 & 25 \\
Average Measures & $\mathbf{0 . 9 9 2}$ & $\mathbf{0 . 9 6 0}$ & $\mathbf{0 . 9 9 8}$ & 214,082 & 25 \\
\hline
\end{tabular}

Table 5. Presentation of the values of statistician K (Cohen's Kappa) and Spearman correlation coefficient for each item individually (as in the work of Franjoine et al. (2003), [9]).

\begin{tabular}{ccc}
\hline Items & Kappa & Spearman \\
\hline $\mathbf{1}^{\text {st }}$ & 1.00 & 1.00 \\
$\mathbf{2}^{\text {nd }}$ & 1.00 & 1.00 \\
$\mathbf{3}^{\text {rd }}$ & 0.49 & 1.00 \\
$\mathbf{4}^{\text {th }}$ & 1.00 & 1.00 \\
$\mathbf{5}^{\text {th }}$ & 1.00 & 1.00 \\
$\mathbf{6}^{\text {th }}$ & 0.641 & 1.00 \\
$\mathbf{7}^{\text {th }}$ & 1.00 & 1.00 \\
$\mathbf{8}^{\text {th }}$ & 0.867 & 0.978 \\
$\mathbf{9 t h}^{\text {th }}$ & 0.784 & 0.995 \\
$\mathbf{1 0}^{\text {th }}$ & 0.627 & 0.903 \\
$\mathbf{1 1}^{\text {th }}$ & 0.716 & 0.733 \\
12th $^{13 \text { th }}$ & 0.838 & 0.789 \\
$\mathbf{1 4}^{\text {th }}$ & 0.842 & 0.884 \\
\hline
\end{tabular}

The results of the present study are in consonance with Franjoine, Gunther and Taylor (2003) [9], PBS tests reliability was very high (ICC $=0.89-0.99$ ). Jin-Gang Her, Ji-Hea Woo and Jooyeon Ko (2012) [13], found great reliability ICC $=0.901$ for the overall PBS score in the first assessment and ICC $=0.988$ in the second assessment. With the research of Snehal, Vijaymuniraj and Solomon (2011) [14], which showed that PBS is a valid scale and therefore can be used in clinical studies to assess balance in children. Finally, the results of this research are in line with the research of Ries, Michaelsen, Soares, Monteiro and Allegretti (2012) [15], where the results showed great reliability in the overall PBS score $(\mathrm{ICC}=0.85)$. As for the intra-observer agreement scores, results were excellent for both observers (ICC $=0.98$ ) which was exceptional as well as those of $\mathrm{Yi}$, Hwang, Kim, Kwon, (2012) [12], Duarte, Grecco, Franco, Zanon, Oliveira, (2014) [16] and Jantakat, Ramrit, Emasithi and Siritaratiwat, (2015) [17], where each research proved that PBS was a valid and reliable tool $(\mathrm{p}<0.001)$. 


\section{Conclusions}

Overall, the results of the present research provided considerable evidence suggesting that the Greek translation of PBS test is reliable and can be used to detect kinetic disorders in children aged 4 to 18 years in the Greek population. More research must be done with a bigger number of participants to investigate and determine the intra-inter reliability of the test.

\section{Limitations}

As to the sample: the sample was only from a small city of Trikala in Greece as the investigation was carried out there.

\section{Conflicts of Interest}

The authors declare no conflicts of interest regarding the publication of this paper.

\section{References}

[1] Shumway-Cook, A. and Woollacott, H.M. (2007) Motor Control-Theory and Practical Applications. 2nd Edition, Lippincott Williams and Wilkins, Philadelphia.

[2] Winnick, J.P. (1979) Early Movement Experiences and Development: Rehabilitation and Remediation. Saunders, Philadelphia.

[3] Eichstaedt, C.B. and Lavay, B.W. (1992) Physical Activity for Individuals with Mental Retardation. Human Kinetics Books, Champaign.

[4] Huxham, F.E., Goldie, P.A. and Patla, A.E. (2001) Theoretical Considerations in Balance Assessment. Australian Journal of Physiotherapy, 47, 89-100. https://doi.org/10.1016/S0004-9514(14)60300-7

[5] Auxter, D., Pyfer, J. and Huettig, C. (2005) Principles and Methods of Adapted Physical Education and Recreation. Mosby-Year Book, Inc., St. Louis.

[6] Islam, M.M., Nasu, E., Rogers, M.E., Koizumi, D., Rogers, N.L. and Takeshima, N. (2004) Effects of Combined Sensory and Muscular Training on Balance in Japanese Older Adults. Preventive Medicine, 39, 1148-1155. https://doi.org/10.1016/j.ypmed.2004.04.048

[7] Riber, R., Mahler, T. and Ishee, J. (1983) Comparison of Static Balance in Trainable Mentally Handicapped and Non Handicapped Children. Perceptual and Motor Skills, 56, 311-314. https://doi.org/10.2466/pms.1983.56.1.311

[8] Sherrill, C. (1993) Adapted Physical Activity, Recreation and Sport. Wm. C. Brown Communications, Inc., Dubuque.

[9] Franjoine, M.R., Gunther, J.S. and Taylor, M.J. (2003) Pediatric Balance Scale: A Modified Version of the Berg Balance Scale for the School-Age Child with Mild to Moderate Motor Impairment. Pediatric Physical Therapy, 15, 114-128. https://doi.org/10.1097/01.PEP.0000068117.48023.18

[10] Franjoine, M.R., Darr, N., Held, S., Kott, K. and Young, B.L. (2010) The Performance of Children Developing Typically on the Pediatric Balance Scale. Pediatric Physical Therapy, 22, 350-359. https://doi.org/10.1097/PEP.0b013e3181f9d5eb

[11] Chen, C., Shen, C., Chen, C., Wu, C., Liu, W., et al. (2012) Validity Responsiveness Minimal Detectable Change and Minimal Clinically Important Change of Pediatric 
Balance Scale in Children with Cerebral Palsy. Research in Developmental Disabilities, 34, 916-922. https://doi.org/10.1016/j.ridd.2012.11.006

[12] Yi, S.H., Hwang, J.H., Kim, S.J. and Kwon, J.Y. (2012) Validity of Pediatric Balance Scales in Children with Spastic Cerebral Palsy. Neuropediatrics, 43, 307-313. https://doi.org/10.1055/s-0032-1327774

[13] Her, J.-G., Woo, J.-H. and Ko, J. (2012) Reliability of the Pediatric Balance Scale in the Assessment of the Children with Cerebral Palsy. Journal of Physical Therapy Science, 24, 301-305. https://doi.org/10.1589/jpts.24.301

[14] Lende, S. and Vijaymuniraj, J.S.M. (2011) Concurrent Validity of Pediatric Balance Scale with Computerized Posturography. International Journal of Current Research and Review, 3, 206.

[15] Ries, L.G., Michaelsen, S.M., Soares, P.S., Monteiro, V.C. and Allegretti, K.M. (2012) Cross-Cultural Adaptation and Reliability Analysis of the Brazilian Version of Pediatric Balance Scale (PBS). Review Brazilian Physiotherapy, 16, 205-215. https://doi.org/10.1590/S1413-35552012005000026

[16] Duarte Nde, A., Grecco, L.A., Franco, R.C., Zanon, N. and Oliveira, C.S. (2014) Correlation between Pediatric Balance Scale and Functional Test in Children with Cerebral Palsy. Journal of Physical Therapy and Science, 26, 849-853.

https://doi.org/10.1589/jpts.26.849

[17] Jantakat, C., Ramrit, S., Emasithi, A. and Siritaratiwat, W. (2015) Capacity of Adolescents with Cerebral Palsy on Paediatric Balance Scale and Berg Balance Scale. Research in Developmental Disabilities, 36C, 72-77. https://doi.org/10.1016/j.ridd.2014.09.016

[18] Portney, L.G. and Watkins, M.P. (2009) Foundations of Clinical Research: Applications to Practice. Pearson/Prentice Hall, Upper Saddle River.

[19] Silkwood-Sherer, D.J., Killian, C.B., Long, T.M. and Martin, K.S. (2012) Hippotherapy-An Intervention to Habilitate Balance Deficits in Children with Movement Disorders: A Clinical Trial. Physical Therapy, 92, 707-717.

https://doi.org/10.2522/ptj.20110081 